\title{
TÂNIA LIMA AYER DE NORONHA E SUA TRAJETÓRIA NO COLÉGIO TÉCNICO DA UFMG
}

\author{
KELLY MARIA DE CAMPOS FORNERO ABREU DE LIMA \\ MELILLO \\ Colégio Técnico da Universidade Federal de Minas Gerais

\section{MARIA LAURA MAGALHÃES GOMES} \\ Universidade Federal de Minas Gerais
}

RESUMO

Este artigo focaliza o percurso (auto)biográfico da professora Tânia Lima Ayer de Noronha, docente de Matemática no Colégio Técnico da Universidade Federal de Minas Gerais (Coltec-UFMG), no período de 1979 a 2002. Esse percurso é estudado a partir de uma investigação anterior que usou a metodologia da História Oral. A fonte principal do estudo é a entrevista da própria Tânia, mas também foram usados documentos escritos e depoimentos de outros entrevistados. Uma discussão sobre a História Oral, uma contextualização do Coltec e a motivação para o estudo são apresentadas, seguidas por destaques do trabalho da professora na escola. Buscou-se enfatizar a forte relação entre a atuação da professora e as características da instituição escolar focalizada, bem como considerar o papel desempenhado por Tânia, vinculando-o à repercussão de questões de gênero. 0 relacionamento com alunos e colegas e a postura de Tânia resultaram no estabelecimento de uma imagem feminina e maternal da professora. O texto é concluído com considerações sobre o percurso de Tânia, à luz da perspectiva de gênero, que estabelece um contraste entre a justificativa da caracterização de homens e mulheres a partir de diferenças sexuais e a construção socio-histórica da feminilidade e da masculinidade.

Palavras-chave: Percursos (auto)biográficos. Participação feminina na História da Educação Matemática. Colégio Técnico da UFMG. História Oral. Gênero.

ABSTRACT TÂNIA LIMA AYER DE NORONHA AND HER TRAJECTORY
IN COLÉGIO TÉCNICO - UFMG
This article focuses on the (auto) biographical trajectory of Tânia Lima
Ayer de Noronha, Mathematics teacher in Colégio Técnico - Universi-
dade Federal de Minas Gerais (Coltec-UFMG) during the period 1979- 
2002. Tânia's pathway is studied based on an earlier research with the use of Oral History methodology. The main source for the study is Tânia's own interview, but written documents and statements from other interviews were considered. A discussion on Oral History, a contextualization of Coltec and the motivation for the study are followed by a section on the highlights of the teacher's work in Coltec. It was our purpose to emphasize the strong relationship between the teacher's performance and the characteristics of the focused school institution, as well as to consider Tânia's role by linking it to the repercussion of gender issues. The relationship with students and colleagues and Tânia's posture had the configuration of a feminine and maternal image for her as a result. The text is concluded with considerations about Tânia's trajectory in the light of the gender perspective, which establishes a contrast between the justification of the characterization of men and women based on sexual differences and a socio-historical construction of femininity and masculinity. Keywords: Biographical (auto) trajectories. Female participation in the History of Mathematics Education. Colégio Técnico-UFMG. Oral History. Gender.

\section{TÂNIA LIMA AYER DE NORONHA Y SU TRAJETORÍA EN}

\section{EL COLEGIO TÉCNICO DE UFMG}

Este artículo se centra en el recorrido (auto) biográfico de la profesora Tânia Lima Ayer de Noronha, docente de Matemáticas en el Colegio Técnico de la Universidad Federal de Minas Gerais (Coltec-UFMG) en el período 1979-2002. Este recorrido se estudia a partir de una investigación anterior que utilizó la metodología de la Historia Oral. La fuente principal para el estudio es la entrevista de la propia Tânia, pero también se utilizaron documentos escritos y testimonios de otros entrevistados. Una discusión sobre la Historia Oral, una contextualización del Coltec y la motivación para el estudio son presentadas, seguidas por los destaques sobre el trabajo de la profesora en la escuela. Se buscó enfatizar la fuerte relación entre la actuación de la profesora y las características de la institución escolar enfocada, así como considerar el papel desempeñado por Tânia vinculándolo a la repercusión de cuestiones de género. La relación con alumnos y colegas y la postura de Tania resultaron en el establecimiento de una imagen femenina y maternal para la profesora. El texto se concluye con consideraciones sobre el recorrido de Tânia a la luz de la perspectiva de género, que establece un contraste entre la justificación de la caracterización de hombres y mujeres a partir de diferencias sexuales 
y la construcción socio-histórica de la feminidad y la masculinidad. Palabras clave: Rutas (auto)biográficas. Participación femenina en la Historia de la Educación Matemática. Colegio Técnico de la UFMG. Historia Oral. Género.

\section{Considerações iniciais}

Este artigo focaliza o percurso (auto)biográfi$\mathrm{co}^{1}$ da professora Tânia Lima Ayer de Noronha, docente de Matemática no Colégio Técnico da Universidade Federal de Minas Gerais (Coltec-UFMG), no período de 1979 a 2002. Esse percurso é estudado a partir de uma investigação cujo objetivo geral foi construir uma história das práticas de ensinar-aprender Matemática, em cursos técnicos do referido colégio, no período transcorrido entre 1969, primeiro ano de seu funcionamento, até 1997, ano que marcou mudanças no oferecimento dos cursos existentes até então devido a alterações na legislação² (MELILLO, 2018). Foram também objetivos da pesquisa: a caracterização da formação acadêmica dos professores de Matemática da escola, para procurar compreender possiveis reflexos dessa formação em sua atuação; conhecer/caracterizar as práticas docentes dos professores entrevistados, buscando descrever a metodologia, os recursos empregados, os materiais didáticos utilizados/produzidos e as

1 Usaremos a palavra (auto)biográfico e suas flexões quando considerarmos a participação de outras fontes na construção do percurso de uma pessoa. No caso deste estudo, é essa a situação, em que pese centralizarmos a abordagem no que a própria professora Tânia narrou a seu respeito. Outras vezes, em geral quando nos referirmos ao enfoque do trabalho, faremos uso simplesmente do adjetivo "autobiográfico" e suas variações.

2 Durante o período de vigência dessa legislação, o Colégio ofereceu Ensino Médio "puro", não profissionalizante, apenas para os alunos oriundos do Centro Pedagógico - escola de nível fundamental vinculada à UFMG. Em contrapartida, os alunos vindos de outras escolas, que ingressavam por concurso, realizavam o Ensino Médio regular articulado às disciplinas dos cursos técnicos. Os alunos concursados obtinham os certificados de Técnico e Ensino Médio, enquanto os egressos do Centro Pedagógico recebiam apenas o diploma de Ensino Médio. tendências conferidas ao ensino de Matemática; identificar e analisar aspectos importantes na constituição dessas práticas, tais como formação acadêmica, pesquisa em Matemática ou em Educação Matemática, questões políticas, motivações pessoais, mudanças curriculares, níveis de articulação com outras disciplinas (de caráter técnico ou não) e autonomia de trabalho; e detectar, descrever e analisar permanências, mudanças ou rupturas ocorridas nas práticas dos professores no contexto e período de referência.

A história elaborada nessa investigação, que usou fontes diversificadas de muitos arquivos, envolvendo documentação institucional, jornais e fotografias, foi construída, especialmente, a partir de depoimentos de sete docentes de Matemática que lecionaram na escola, oito ex-alunos e um ex-diretor, obtidos em entrevistas com o uso da metodologia da História Oral. Entre os docentes, encontra-se a professora Tânia Lima Ayer de Noronha, que atuou no Coltec de 1979 a 2002 e concedeu sua entrevista para a primeira autora deste artigo, em 16 de março de 2016.

A entrevista de Tânia, conduzida a partir de um roteiro que buscou contemplar os objetivos explicitados anteriormente, assim como as dos outros colaboradores, foi gravada e posteriormente transcrita. De acordo com os princípios da metodologia da História Oral que adotamos, o texto transcrito recebeu também o tratamento denominado textualização, pelo qual foram retiradas as marcas mais fortes da oralidade e os relatos foram reordenados cronológica ou tematicamente. Posteriormente, 
Tânia, do mesmo modo que os outros entrevistados, leu a textualização e, tendo solicitado pequenas modificações que foram efetivadas, autorizou seu uso na pesquisa. ${ }^{3}$ Este artigo se baseia, em sua maior parte, em uma releitura da narrativa de Tânia, modo como nos referimos à textualização de sua entrevista. No entanto, também utilizamos outros depoimentos, manifestados nas entrevistas concedidas por alunos e outros professores para a mesma investigação sobre o Colégio Técnico.

Como o presente trabalho constitui-se como um estudo de relatos produzidos visando outra investigação, vale observar que nossas fontes, revisitadas agora, foram geradas a partir de um determinado contexto e de perguntas específicas, criadas para alcançar determinados objetivos, que não estavam explicitamente relacionados a gênero ou a especificidades da participação feminina na docência em Matemática. Contudo, as lembranças de Tânia nos chamaram a atenção para esses aspectos, pela relação afetuosa que essa docente tinha com os seus alunos e alunas e seu forte envolvimento com as questões pessoais e familiares deles e delas.

A escolha de estudar mais de perto o percurso (auto)biográfico de Tânia tem sua motivação em alguns traços de seu perfil como professora de Matemática no Coltec. Queremos ressaltar nossa percepção da forte relação estabelecida entre os modos como essa docente atuou no Coltec e as características da escola, além de considerar o papel desempenhado pela professora vinculando-o à repercussão de questões de gênero. Assim, um de nossos propósitos é destacar aspectos configurados a partir da especificidade da condição feminina e dos modos como essa especificidade se traduziu nas práticas pedagógicas de Tânia (CATANI; BUENO; SOUSA; SOUZA, 2000). Consideramos a

3 O projeto da referida pesquisa foi aprovado pelo Comitê de Ética em Pesquisa da UFMG, em 25 de fevereiro de 2015. O número do parecer é 964.792 . abordagem autobiográfica extremamente importante para "tentar compreender a maneira com que professores e alunos reconstruíram sua experiência, como constituíram relações, estratégias, significações por meio das quais construíram a si próprios como sujeitos históricos" (SOUZA, 2000, p. 52).

Este artigo se organiza em diversas seções a partir desta introdução. Na primeira, discorremos sobre a metodologia da História Oral em nossa pesquisa. Em seguida, apresentamos brevemente a trajetória de criação do Colégio Técnico e descrevemos algumas de suas características. Posteriormente, após expor a motivação para focalizar o percurso (auto)biográfico de Tânia, discorremos acerca dos destaques desse percurso. Concluímos o texto com considerações sobre esse percurso iluminadas pela perspectiva de gênero.

\section{A metodologia da História Oral e a construção de percursos (auto) biográficos}

Tal como na pesquisa revisitada (MELILLO, 2018), na qual demos ênfase ao uso das vozes na construção de fontes históricas, neste trabalho, as vozes são os alicerces para a construção de um percurso (auto)biográfico da professora Tânia Ayer. A oralidade permite valorizar os sujeitos, seus pontos de vista, suas subjetividades. Assim como assinala Garnica (2007), acreditamos que, diante da impossibilidade de constituir uma única história, a História Oral pode:

[...] registrar algumas de suas várias versões, aos olhos de atores sociais que vivenciaram certos contextos e situações, considerando como elementos essenciais nesse processo as memórias desses atores - via-de-regra negligenciados pelas abordagens sejam elas oficiais ou mais clássicas - sem desprestigiar, no entanto, os dados 'oficiais', sem negar a importância das fontes primárias, dos arquivos, dos monu- 
mentos, dos tantos registros possiveis, os quais consideramos uma outra versão, outra face dos 'fatos'. (2007, p. 13)

Ao ouvirmos a professora Tânia, além de conhecermos sua formação, os materiais didáticos que utilizou e facetas de sua metodologia de ensino, criamos situações de sala de aula, escutamos sobre sentimentos, lembranças, esquecimentos, impressões, opiniões e individualidades dessa docente. A criação de registros que partem da oralidade retoma evidências e elementos que seriam dificilmente contemplados com outras fontes. Por outro lado, o reconhecimento e o uso dos documentos escritos, fotografias e impressos auxiliam na construção da história do Coltec, das práticas de ensino de Matemática e, particularmente, das memórias de Tânia.

A História Oral é aqui vista não apenas como um conjunto de procedimentos, mas também como fundamentação teórica, já que buscamos ir além de constituir fontes intencionalmente, procurando conhecer o "porquê" de cada escolha metodológica (GARNICA, 2015).

Como comentado antes, Melillo (2018) realizou 16 entrevistas, que envolveram oito ex -alunos, sete ex-professores de Matemática e um ex-diretor do Coltec-UFMG. 0 roteiro inicial utilizado possibilitou abertura para valorizar as experiências relatadas pelos colaboradores. Alguns entrevistados, por exemplo, optaram por realizar uma fala introdutória, relacionada ou não à pesquisa. Antes do início da gravação da entrevista com a professora Tânia Ayer, ela falou, à primeira autora, de suas duas filhas, orgulhosa das opções que cada uma delas seguiu. Além disso, contou sobre quando se aposentou e decidiu acompanhar profissionalmente o marido em seu empreendimento comercial. Entrevistadora e entrevistada conversaram sobre assuntos diversos, que extrapolaram o tema da investigação sobre o colégio.
É importante descrever a postura adotada durante as entrevistas, que se caracterizou pela busca por interagir com os colaboradores e cativá-los, para tê-los efetivamente como interlocutores. Ao mesmo tempo que os ouvia com atenção, a entrevistadora contestava-os ou interrogava-os, eventualmente, procurando não quebrar a interlocução (GARNICA, 2007).

As entrevistas foram gravadas, transcritas, textualizadas, modificadas a partir de diálogos com os entrevistados, de modo que as diversas formas adquiridas pelos relatos resultaram das interações entre a entrevistadora e os colaboradores. Na validação das textualizações, cada depoente conferiu o texto e corrigiu erros e enganos, acrescentando ou suprimindo alguma informação, legitimando o trabalho realizado (MEIHY; RIBEIRO, 2011). ${ }^{4}$

Nesse exercício de produzir fontes, não se espera reconstituir o passado, mas compreender como situações foram apreendidas e interpretadas por sujeitos que as vivenciaram, acompanharam ou observaram. Alberti (2013) explica que conhecer diferentes visões do passado nos permite ampliar o conhecimento sobre ele a partir de perspectivas particulares, de compreensões e experiências individuais de pessoas que testemunharam certos acontecimentos. Desse modo, é possivel estabelecer relações "entre o geral e o particular mediante análise comparativa de diferentes testemunhos, e tomar as formas como o passado é apreendido e interpretado por indivíduos e grupos como dado objetivo para compreender suas ações" (2013, p. 26). Tendo como diretrizes essas considerações, debruçamo-nos sobre aquilo que Tânia, professora, pesquisadora, esposa, mãe e cuidadora do lar narrou. Além do interesse pela sua atuação como mulher e educadora, quisemos valorizar, neste trabalho, a vinculação do trabalho de Tânia com uma

4 As 16 textualizações encontram-se, na íntegra, nos apêndices do trabalho de Melillo (2018). 
escola técnica inserida em uma grande universidade pública, na qual os docentes eram mobilizados a investir na pesquisa, no aprimoramento das metodologias de ensino, na capacitação profissional e no trabalho de divulgação e repercussão de seus conhecimentos e práticas, por meio de cursos e palestras ministrados a outros professores.

Nesse cenário, como veremos adiante, Tânia chamou nossa atenção pelas suas particularidades, reconhecidas e compartilhadas pelos seus colegas de trabalho. Parece-nos que algumas das ações dessa professora só foram possíveis devido à sua atuação no Coltec, uma escola de ensino técnico, nível médio, vinculada à UFMG. Diante disso, julgamos importante caracterizar a instituição e o cenário evocados nas lembranças de Tânia.

\section{O Colégio Técnico da UFMG}

o Coltec foi criado para formar recursos humanos para atuar, especialmente, nos laboratórios de pesquisa da universidade, impulsionando o desenvolvimento científico. De acordo com o Jornal do Brasil, publicado em 10 de novembro de $19699^{5}$, "Formar técnicos de nivel médio para laboratórios médicos de pesquisa e industriais é o objetivo do Colégio Técnico da UFMG [...]" (1969, p. 47). ${ }^{6}$

Bem equipado com bibliotecas, laboratórios e oportunidades de estágio, o Coltec representava uma alternativa profissional para conter a demanda de concluintes do 2 o grau que não conseguissem ou não quisessem acesso aos cursos superiores, no final da década de 1960.

Entretanto, a boa qualidade da formação geral dos estudantes egressos do Colégio motivava muitos deles a buscarem (e alcançarem)

5 Jornal do Brasil, 10 nov. 1969, p. 47.

6 Os recortes de jornais citados no texto encontram-se disponíveis para consulta no Apêndice da tese de Melillo (2018). a aprovação em cursos superiores, o que descaracterizava os objetivos iniciais de criação da instituição. Nesse cenário, o processo seletivo da escola, constituído por prova escrita, passou a reservar vagas, a partir de 1971, para estudantes de baixa renda ou da zona rural. Era uma iniciativa para captar o maior número de alunos com potencial para exercer a profissão de técnico de laboratório.

É muito importante salientar que a concepção do Coltec como escola de formação técnica está essencialmente ligada a seu modo de criação. A fundação do Colégio ocorreu a partir de um convênio firmado com o Governo Britânico, ${ }^{7}$ que se comprometeu a enviar sete especialistas ingleses ao Brasil; fornecer treinamento de oito profissionais brasileiros; e contribuir com o subsídio de quinhentos e cinquenta mil cruzeiros [55 mil libras esterlinas $^{8}$ ], aproximadamente, para a aquisição de material específico. ${ }^{9}$ Como parte do acordo de criação, o Governo Brasileiro responsabilizouse por "fornecer as instalações necessárias dentro do campus da UFMG: móveis e equipamentos menores, ensino adequado e pessoal auxiliar e fornecer verbas para o pagamento de despesas anuais".10

Instalado no campus da UFMG, em Belo Horizonte, no local onde funcionava anteriormente o "Instituto de Mecânica" da Escola de Engenharia, o Coltec oferecia os cursos técnicos de Patologia Clínica, Instrumentação, Eletrônica e Química.

Por localizar-se dentro do campus da Universidade, não havia muros cercando o Colégio, como ocorre na maioria dos prédios escolares. No entanto, uma extensão significativa do campus da UFMG, percorrida pelos alunos em direção ao Coltec, funcionava como um

7 Esse convênio foi encerrado em 1977.

8 Disponivel no documento "Convênio para a criação e implantação do Colégio Técnico da Universidade Federal de Minas Gerais" (MELILLO, 2018).

9 Jornal Diário da Tarde, 3 dez. 1970, p. 8.

10 Jornal Diário da Tarde, 3 dez. 1970, p. 8. 
grande pátio escolar, separando a escola da rua, e operando como espaço de transição. Em outras palavras, a passagem de uma ordem, ou uma cultura, para outra (FARIA FILHO, 1998).

Essa ausência de muros permitia que os alunos do Colégio Técnico frequentassem vários ambientes externos, no entorno da escola e em outros prédios da Universidade. 0 prédio do colégio era cercado de área verde, com muitos gramados e árvores. Uma árvore, em particular, ficou conhecida pelos estudantes como a "Árvore da Paz". Alguns dos entrevistados para a pesquisa sobre o Colégio referiram-se à sombra dessa árvore como o principal lugar em que estudantes se reuniam para consumir drogas, sobretudo maconha.

Entre as características do Coltec, não podemos deixar de realçar a liberdade oferecida aos alunos, destacada nos depoimentos dos nossos colaboradores e em pesquisas acadêmicas que tiveram o Colégio como objeto ou cenário de investigação. Na prática, essa “liberdade" estava relacionada, principalmente, ao:

fato de poderem entrar e sair a qualquer momento da escola e das aulas; de serem isentos do uso de uniforme; de inexistir um disciplinário e de não haver muros ao redor do prédio. Além disso, os alunos podem namorar (desde que obedecendo a certos 'limites') e fumar nas áreas externas da escola. (VILLAS, 2009, p. 73)

Além disso, os cursos realizavam-se em tempo integral, de 7:30h às 17:30h, o que contribuía para o estabelecimento de laços fortes entre os estudantes. A convivência era constante: nas salas de aula, no almoço, lanches, momentos de estudo, sonecas, desabafos, conflitos, entre outros. Desse modo, muitas vezes os alunos compartilhavam mais tempo com seus colegas do que com seus familiares.

Havia, ainda, a interação dos estudantes do Coltec com os estudantes universitários. Estando dentro da UFMG, era natural que os alunos, denominados "coltecanos", frequentassem outras unidades acadêmicas da UFMG, além de restaurantes, clubes e bibliotecas. Nesses ambientes, faziam amizades e vivenciavam situações comuns a adultos jovens, com idade superior a 17 anos.

Sob outra ótica, a localização do Colégio no campus universitário e o regime de trabalho, na maioria das vezes, de dedicação exclusiva à escola, foram estímulos inegáveis para que seus docentes desenvolvessem pesquisas e atividades de capacitação. Adicionalmente, participavam ativamente na formação continuada de outros docentes, seja recebendo estagiários das licenciaturas ou promovendo palestras, cursos e projetos de extensão. Esse conjunto de fatores, aliados à estrutura fisica, bem equipada, oferecia oportunidades, para atuação dos professores, que ultrapassavam as aulas de Matemática ministradas cotidianamente aos estudantes.

A professora Tânia trabalhou por cerca de 23 anos nesse contexto e condições, tendo desenvolvido um amplo espectro de atividades, conforme será abordado adiante. Considerando os depoimentos coletados para a pesquisa de Melillo (2018), Tânia fez tudo isso com toque especial, percebido socialmente como feminino e maternal.

\section{Motivação para o estudo do perfil de Tânia e sua atuação no Coltec}

0 enfoque autobiográfico oferece contribuições relevantes naquilo que concerne ao que a educação realizou no passado. Ele conduz à inclusão do ponto de vista de alunas e professoras, ultrapassando discursos em geral mais frequentemente evidenciados e valorizados, como os dos governos, dos autores de programas e de livros didáticos, ou de outros sujeitos que, em determinado momento, tiveram algum tipo de destaque nos meios educacionais. 
$\mathrm{Na}$ investigação acerca da presença feminina em diversos momentos e contextos, merecem particular atenção os relatos autobiográficos quanto à educação familiar e escolar que as mulheres receberam, em que repercutem estereótipos de gênero referentes à educação feminina. Nesses relatos, está implicada a conferência de destaque à identificação, vocação ou interesse pelos conhecimentos matemáticos das mulheres, sejam eles reconhecidos como marcantes ou como ausentes. Do mesmo modo, torna-se relevante examinar aspectos das carreiras profissionais das mulheres em sua atuação como professoras ou autoras de livros didáticos e outros textos voltados para o ensino da Matemática. É, pois, nesse contexto, que situamos o presente estudo sobre a professora Tânia.

Tânia foi convidada a conceder uma entrevista para a pesquisa sobre as práticas de ensinar-aprender Matemática no Coltec porque 18 anos de seu trabalho como professora de Matemática nessa escola estão contidos no período que desejávamos investigar. Antes do contato com ela, funcionários do colégio diziam frequentemente: "A professora Tânia era muito bonita e elegante!" "Os alunos até compuseram uma música para falar de sua beleza". "Ela era muito elegante, sempre cheirosa". Ou ainda, elogiavam o seu carisma com os alunos, dizendo que ela era uma "mãezona", que acoIhia e dava muita atenção aos alunos.

o que se destacou muito na personalidade de Tânia e particularmente em sua atuação no Coltec foi a relação de forte compromisso em relação aos alunos, que ultrapassava muito sua responsabilidade de lecionar Matemática. Notamos, em sua narrativa e também em depoimentos de outros entrevistados, que ela exercia a profissão com carinho e afeto e sua postura e gestos the conferiram uma imagem predominantemente maternal. Essa imagem se sobressaiu nas muitas vezes em que a pala- vra "mãezona" foi usada em referência a Tânia. Ao escutar seu relato e ler sua narrativa, percebemos que ela esperava que os estudantes, mesmo aqueles que não se envolviam com a disciplina, por gratidão ao seu empenho em ensinar, fizessem as atividades propostas e estudassem. Tânia disse ter estado sempre disponivel para atender os alunos em suas dúvidas. Durante o período de sua atuação no Coltec, produziu materiais, realizou treinamentos para melhorar o seu desempenho e participou de ações de capacitação de outros docentes.

Fora das salas de aula, Tânia acompanhava estudantes com problemas familiares ou usuários de drogas. Ela os ouvia, aconselhava e ajudava no que estivesse ao seu alcance. No caminho para a escola, Tânia oferecia carona aos estudantes, que a aguardavam no caminho. No retorno, as caronas se repetiam. Um por um, ela os deixava nas proximidades de suas casas.

Nas práticas de ensinar Matemática, Tânia trabalhou em sintonia com outros professores do colégio, e investiu intensamente em atividades com os estudantes reunidos em grupos, usando, sobretudo, dois recursos metodológicos: os estudos dirigidos e as instruções programadas.

A seguir, focalizamos a narrativa de Tânia, recorrendo por vezes a falas de outros entrevistados de modo a conferir ênfase a vários aspectos específicos de sua trajetória.

\section{Destaques do percurso (auto)biográfico de Tânia: relacionamento com os estudantes, práticas de ensino, atuação no grupo de professores do Coltec}

Na narrativa de Tânia, sobressaiu-se com muita força a forma como se relacionou com os 
estudantes, em todas as fases de sua carreira docente, e, particularmente, na escola pesquisada, o Coltec-UFMG. A dimensão maternal de sua atuação no Colégio avultou tanto em suas próprias palavras, como nas de outros entrevistados. É interessante a reflexão que ela realizou a respeito de sua postura, relacionando -a a sua própria formação escolar:

Curiosamente, em minha formação, eu estudei em escolas rígidas, de freira. Desde então, eu decidi que não reproduziria aquelas formas de ensino e aprendizagem, caso me tornasse professora. ${ }^{11}$

Vemos que Tânia, muitos anos depois de concluída sua educação escolar, ao evocar o passado com os olhos do momento da entrevista, recordou-se da atitude rígida de professores e gestores das instituições que frequentou, e considerou que o que fez como professora resultou de uma decisão consciente de contrapor-se a essa atitude. Além do Colégio Técnico, instituição em que trabalhou durante a maior parte de sua carreira, Tânia lecionou em faculdades particulares e escolas de nivel correspondente ao atual Ensino Fundamental. Em particular, ela rememorou sua experiência numa escola de Belo Horizonte que não existe mais hoje, a Escola Picapau Amarelo, considerada inovadora em relação aos padrões vigentes em sua época. Essa instituição, criada em 1968 pela professora Maria Magdalena Lana Gastelois, "buscava uma educação diferencia$\mathrm{da}$, tendo por objetivo ser uma escola onde as crianças poderiam crescer e aprender em contato com as outras crianças em um ambiente cercado por diferenças e propiciando novas descobertas".12 Ao rememorar essa escola e seu trabalho nela, Tânia disse:

\footnotetext{
11 Apresentaremos em itálico trechos da entrevista de Tânia e de outros colaboradores. Os extratos da narrativa de Tânia foram extraídos de Melillo (2018, p. 444455).

12 Disponível em: <http://www.ufop.br/noticias/palestra-sobre-a-escola-picapau-amarelo-com-magdalena-lana>. Último acesso em: 13 fev. 2017.
}

A escola Picapau Amarelo pertencia a uma ex-professora do Coltec, Magdalena, do Departamento de Português. [...] Essa escola era fabulosa! Era para quem acreditava que se podia ajudar o aluno a construir o conhecimento através de experimentações. Eu acreditava nisso! Eu exercia a minha função com muito rigor, muita credibilidade. Para ensinar volume para os meninos desse colégio, por exemplo, nós nadávamos com eles. Era muito interessante! Aos olhos de muitos colegas, que ouviam os meus relatos sobre as aulas no Picapau Amarelo, essas eram soltas, sem controle. Mas eu sempre esclarecia, que na hora de trabalho era trabalho. Eu era muito rigorosa e muito enérgica. Os alunos falavam isso comigo, inclusive.

A proximidade com os/as estudantes e o relacionamento carinhoso com eles e elas foram destacados na narrativa da professora, nas diversas escolas em que lecionou. Tânia enfatizou que a relação estreita com alunos e alunas teve início antes de seu ingresso no Coltec e relatou histórias semelhantes sobre esse tema desenroladas em todas as instituições em que lecionou, mostrando que se encontrava com os estudantes também fora do ambiente escolar, desde o início de sua atuação docente.

Os alunos do Picapau Amarelo, durante as tardes, iam lá para minha casa, tomar café com a minha mãe, mesmo eu estando fora, realizando um curso. Eles atravessavam a Avenida do Contorno para visitarem a minha casa. No retorno deles, minha mãe ficava preocupa$d a$, e pedia que nossa empregada os ajudasse a atravessar a avenida. Depois de formada, quando lecionei no Colégio Imaculada Conceição, ${ }^{13}$ isso se repetiu. Os alunos me viam ali, sa-

13 No ano de 1534, cinco "Filhas de Jesus" (seguidoras de Jesus Cristo e dedicadas à educação cristã) instituíram, na cidade de Belo Horizonte, mais um colégio da Congregação Filhas de Jesus, denominado Imaculada Conceição. Atualmente, oferece educação infantil, ensino fundamental e médio e educação para jovens e adultos. Disponivel em: <http://www.cicbh.com.br/>. Último acesso em: 06 mar. 2017. 
biam que eu morava perto, que era comum eu receber alunos na minha casa, então iam me visitar também. Eu recebia os meninos, conversava com eles... Depois foram os alunos do Coltec, que me visitavam nessa casa, até eu me casar e sair de lá.

A narrativa deixou claro que o Coltec e seus alunos marcaram positivamente a vida profissional de Tânia, que se referiu às qualidades dos estudantes e às oportunidades que tiveram na escola. Ela também acentuou que a excelência desses alunos se vinculava indubitavelmente ao caráter seletivo imprimido a seu ingresso na escola.

É sempre bom falar do Coltec e relembrar momentos que eu vivi no Colégio. Lembro-me bem da excelência dos alunos e das oportunidades que a escola oferecia a eles. O Coltec era frequentado por meninos, jovens, que tinham a oportunidade de conhecer, pesquisar, se envolver, de fazer de fato, de ir a campo mesmo, de viajar, de participar de feiras...

Os alunos do Coltec eram diferentes, maduros, eram espetaculares e muito selecionados. Afinal, para entrar no Colégio era necessário fazer uma prova de seleção, logo, os meninos que entravam lá eram assim, extraordinários!

A disponibilidade da professora em se relacionar de maneira muito próxima aos estudantes levou-a a participar de um trabalho específico desenvolvido no Coltec e proposto, segundo Tânia, por Leila Marques, professora de História da escola, que trouxe essa ideia de estudos realizados na França. Nas palavras de Tânia:

Nesse trabalho, todas as turmas de 10 e 2 음 anos tinham um professor responsável, o tutor. Não havia muitos docentes participantes, pois tratava-se de um trabalho voluntário. Cada tutor se reunia com a parte interessada da turma. Muitas vezes a turma inteira se envolvia $e$ participava. No horário do almoço, o tutor e os estudantes conversavam e realizavam dinâmi- cas sobre assuntos diversos: violência, drogas, sexo, jogos de azar, rendimento escolar, comportamento e outras temáticas. A gente refletia sobre o amadurecimento da vida e as oportunidades que eles possuíam. Eu dizia a eles que bastava o interesse e a sabedoria deles para aproveitarem.

A professora ressaltou a importância da tutoria ao considerar que a liberdade oferecida pela escola algumas vezes representava, para os estudantes, dificuldades no sentido de lidar com ela e, ao mesmo tempo, ter um bom desempenho escolar.

Na minha concepção, este trabalho criava um vínculo e uma relação de confiança entre estudantes e professores. Os alunos sabiam que estávamos ali, querendo o melhor para eles. Era espetacular poder mostrar para eles que eu estava ali, não somente para ensinar Matemática ou exercer um papel acadêmico, mas para orientar e levar reflexões para toda a vida desses alunos.

Era notável como esse trabalho de tutoria guiava e direcionava ações de muitos dos estudantes do Colégio. Afinal, eram excelentes estudantes, com muito potencial, mas que, ao ingressarem no Coltec, muitas vezes, se deslumbravam com a autonomia oferecida e não aproveitavam as oportunidades. Dessa forma, nós os questionávamos: "O que vocês querem para vocês?" Essas conversas, em parte, inibiam que os alunos faltassem às aulas para bater papo ou ficar sob a "árvore da paz". Vários alunos, não só os do Coltec, mas também os do ICEx, ${ }^{14}$ da Química, dos cursos de graduação próximos, ficavam debaixo da "árvore da paz", usando drogas.

Tânia destacou que o projeto de tutoria foi realizado na escola antes que ela contasse com um setor de Psicologia que, segundo ela, "auxiliava nessas questões pessoais dos estu-

14 Instituto de Ciências Exatas, cujos prédios no campus da UFMG são vizinhos ao do Colégio Técnico. 
dantes" (MELILLO, 2018, p. 448) anteriormente atendidas pelos professores.

Além da participação no projeto formal de tutoria, os contatos de Tânia com os alunos e alunas ocorriam em outras oportunidades, dentro e fora da sala de aula. Ela elaborou um autorretrato relativo às atitudes que teve com eles, esclarecendo as razões da imagem maternal que se associou à sua figura, ao longo dos anos em que lecionou no Coltec. Percebemos que fez questão de sublinhar que a proximidade era estabelecida em limites que procurava fixar.

No Coltec eu era tida como a mãezona, pois eu nunca fui de brigar com os estudantes. Eu gostava de conversar com os alunos que apresentavam algum problema de comportamento na sala de aula. Eu nunca gritei com um aluno em sala de aula, do tipo: "Sossega, senta!" No final da aula eu olhava para o estudante e falava para ele: "Você tem que passar lá no meu gabinete para a gente conversar. Enquanto você não passar lá, você não volta para minha aula". Em nossa conversa, eu explicava as regras estabelecidas, a função de cada um, $e$ falava sobre respeito. Eu dizia a eles que se quisessem podiam ficar brincando no corredor, que ninguém os tiraria dali, mas que na sala de aula eles precisavam obedecer às regras. Nós tínhamos autonomia para agir dessa forma no Colégio. Essa era a minha forma de ser com os meninos, era o meu perfil.

Fora da sala de aula, Tânia relatou ter dado muitas caronas para os meninos e meninas, que a esperavam em um "ponto de carona". Lembrou-se de sempre ter tido "carros grandes, próprios para viagens", nos quais "cabiam muitos meninos".

Focalizemos agora, seguindo o relato autobiográfico da professora, a relação com os alunos do ponto de vista do ensino de Matemática, que se harmoniza com a característica geral de acolhê-los manifestada nos trechos transcritos anteriormente. As atividades de sala de aula desenvolvidas em grupos foram postas em relevo em suas falas, que investiram em palavras como "acolhedora", "confiança", "afeto", "conquistar". No atendimento das dúvidas individuais, ela relatou que se sentava ao lado de cada um e pedia que explicasse o que não tinha entendido. A afetividade foi realçada como fundamental para o sucesso da aprendizagem:

A gente ia dialogando, com muito afeto, até o aluno entender. Eu partia do seguinte princípio: "Os alunos não escolhem os seus professores, e os professores não escolhem os seus alunos". Mas se existe um afeto, tudo se torna mais fácil. Dessa forma, mesmo aqueles alunos que relatavam que não gostavam de Matemática afirmavam: "A Tânia é tão bacana, não vou decepcionar ela. Ela empenha, faz tudo o que pode para que sejamos bem-sucedidos". Eu tinha o princípio de conquistar o meu aluno. E eu conseguia.

Tânia acredita que sua forma de trabalho, "acolhedora", foi aproveitada especialmente para lecionar para os alunos do 10 ano, que ingressavam na escola, "geralmente, com muitos receios e muita insegurança". Havia estudantes que se considerava apresentar "falta de base", entre os quais estavam aqueles oriundos do Centro Pedagógico, escola de 1o grau/Ensino Fundamental da UFMG que, diferentemente dos outros, não precisavam passar por exames de seleção para entrar no Coltec. Percebendo suas dificuldades, oferecia-lhes ajuda em Matemática e era também requisitada por alunos que the confidenciavam "questões pessoais e familiares", relacionadas a drogas, violência e até mesmo abuso sexual, por gostarem da professora e confiarem nela.

A professora salientou que o modo como conduzia suas práticas de ensino no Colégio Técnico não era sempre possível em outras escolas; procurou evidenciar que o ambiente do 
colégio favoreceu essas maneiras de atuar. Notamos que, em tais circunstâncias, o trabalho realizado foi considerado prazeroso e gratificante pela docente:

Me motivou trabalhar no Coltec por tratarse de um ambiente em que eu poderia implantar novas ideias, trabalhar em grupos, de forma autônoma. Onde os meninos transitavam na sala de aula, cortavam, produziam... Eu também pude trabalhar dessa forma no "Pica-Pau Amarelo". Mas, por outro lado, em outras escolas que eu trabalhei, quando eu tentava aplicar essas práticas, eu era vigiada e regulada por disciplinários.

Como outros professores do Colégio Técnico, Tânia acentuou que o ensino de Matemática que ela e outros colegas praticaram contava com poucas aulas expositivas, baseando-se, principalmente, em tarefas para serem realizadas em grupos propostas em apostilas preparadas pelos docentes. Ela e outros professores tinham como propósito a leitura e a participação dos estudantes, orientados pelos docentes quando tinham dúvidas. Tânia tornou-se professora do Coltec após ter sido aprovada num concurso em 1979, ano em que a instituição completou 10 anos de funcionamento. Ela assinalou que deu continuidade ao tipo de atividades de ensino desenvolvidas pelos professores de Matemática que já atuavam na escola antes de seu ingresso.

Os alunos resolviam as questões propostas na própria apostila e faziam alguns registros no caderno, quando necessário. Os professores conferiam os resultados, circulavam orientando-os durante todo o tempo de aula e marcavam no diário a participação dos alunos. A gente sempre trabalhava de forma a levar o aluno a ler a Matemática. [...] 0 mais importante não era os alunos acertarem as questões propostas no material, mas eles participarem. À medida que eles iam fazendo, as dúvidas apareciam $e$ a gente estava ali para orientar.
Quando os alunos concluíam as tarefas, eu corrigia em grupo, tirava as dúvidas em grupo. Se eu percebesse que a dúvida era geral, ou seja, que vários estudantes me chamavam ao mesmo tempo, estando todos eles no mesmo ponto da apostila, aí eu ia para o quadro esclarecer aquela dúvida. Essa dinâmica já era aplicada pelos professores que estavam no Coltec quando eu cheguei.

Entre os recursos que atendiam a essa proposta de trabalho, um grande destaque na narrativa de Tânia, presente também nos relatos de outros professores de Matemática do colégio, foi a referência ao uso intenso de estudos dirigidos e instruções programadas. Os depoimentos de José Eloisio Domingos (Jed) e Abdala Gannam, ${ }^{15}$ colhidos para a investigação acerca das práticas no Coltec, trazem uma breve descrição dos estudos dirigidos e instruções programadas. Jed explicou:

Tínhamos coleções que ficavam disponiveis na biblioteca do Colégio. [...] Os Estudos Dirigidos eram elaborados a partir dessas coleções ou de livros que eram indicados para os alunos comprarem. Esses pareciam com um roteiro, uma orientação para os estudantes seguirem o livro. O objetivo era ajudá-los a ler $e$ entender os conteúdos dos livros. As Instruções Programadas, por sua vez, eram textos, com lacunas para serem preenchidas, para os alunos completarem. Havia perguntas com espaços brancos para as respostas. Em ambos, Instrução Programada e Estudo Dirigido, incluíamos exercícios.

Nas palavras de Abdala:

Produzi muito material para o Departamento de Matemática do Coltec. Escrevi muitas apostilas, Estudos Dirigidos e Instruções Programadas.

Vou exemplificar como fazíamos o Estudo Dirigido: primeiro o aluno é convidado a ler um

15 Jed foi entrevistado em 02/05/2016 e Abdala em 10/03/2016. 
texto. Depois são inseridas perguntas e exercícios do texto, cujas respostas demandam interpretação. Eu indicava muito o livro do Trotta. ${ }^{16}$ [...]

Na Instrução Programada, uma informação pequena é fornecida. Em seguida, trabalha-se com esse dado passo a passo. Não havia, como no Estudo Dirigido, a leitura de um texto base.

Jed e Abdala tornaram-se professores do Coltec bem antes de Tânia, tendo ambos ingressado na escola em 1970. Abdala aposentou-se em 1992, dez anos antes de Tânia, e Jed em 1999. A presença de materiais como os estudos dirigidos e as instruções programadas no período em que atuaram na escola conecta-se à difusão, a partir do final dos anos 1960, precisamente nos primeiros anos de funcionamento do Coltec, de uma tendência pedagógica de repercussão significativa no Brasil, o tecnicismo. Essa tendência, que foi introduzida nas discussões metodológicas e práticas dos professores de Matemática, segundo Saviani (2007), tinha como propósito uma organização racional do ensino que diminuía as interferências subjetivas que poderiam alterar o rendimento dos procedimentos. A disseminação das propostas tecnicistas incluiu divulgar a instrução programada e o estudo dirigido como instrumentos importantes.

De acordo com a professora Maria do Carmo, entrevistada em 04/05/2016, que lecionou no colégio de 1979 a 1995 e tinha concluído um ano antes o mestrado no programa pioneiro interdisciplinar em Ensino de Ciências e Matemática oferecido pela Organização dos Estados Americanos (OEA), na Universidade Estadual de Campinas (Unicamp), dirigido por Ubiratan D'Ambrosio (MUNIZ, 2013):

Durante um certo período, o uso dessas propostas foi difundido na Universidade, onde

16 Trata-se da coleção "Matemática Aplicada", de autoria de Fernando Trotta, Luiz Márcio Imenes e José Jakubovic, publicada em 1980 pela Editora Moderna. (TROTTA; IMENES; JAKUBO, 1980). eram justificadas e fundamentadas por teorias. Em cada época havia uma prática sendo incentivada, como acontece atualmente. Nessa épo$c a$, veio a onda da instrução programada e do estudo dirigido.

Notamos que Tânia aderiu totalmente ao uso desses materiais, mesmo tendo passado a integrar o setor de Matemática muito tempo depois dos primeiros docentes que os empregaram no Coltec. Cabe salientar que a produção dos estudos dirigidos e instruções programadas era favorecida pelas condições de trabalho na escola - os docentes tinham, quase sempre, regime de dedicação exclusiva, e pela disponibilidade de material necessário, como papel, máquinas de escrever e mimeógrafos.

A ênfase nesse tipo de material permaneceu nas práticas docentes de Tânia, mesmo no final dos anos de 1980 e na década de 1990, quando a perspectiva tecnicista não era mais dominante no cenário do ensino de Matemática no Brasil. É interessante registrar o depoimento de Airton Carrião Machado, outro professor do colégio que colaborou na pesquisa, entrevistado em 08/03/2016, que ingressou em 1992 depois de aprovado em concurso. Ao comentar as práticas de ensino de Matemática desenvolvidas por Tânia e outros colegas, ele disse:

Já a professora Tânia, eu tenho conhecimento de que ela dava aula em um modelo tecnicista, aquele em que você vai deixando lacunas para o aluno ir preenchendo e tal. Essa metodologia me incomodava um pouco. Era um pouco da ideia de Estudos Dirigidos, do modelo tecnicista que não me agradava, grande parte elaborado pelo professor Reginaldo ${ }^{17} e$

17 Reginaldo Naves de Souza Lima dedicou-se ao estudo e à criação de novas propostas de aprendizagem de Matemática. Cursou bacharelado em Matemática na UFMG, mestrado em Ciências e Matemática na UNICAMP e mestrado em Educação na UFMG, além de outros cursos. Ganhou medalha de Honra do Mérito Educacional, por sua participação na elaboração da nova proposta curricular de Matemática do Estado de Minas Gerais. Disponível em: <https:/ / issuu.com/sergioluz/docs/p_ame>. Último acesso em: 07 jul. 2016. 
pela professora Maria do Carmo. Num certo momento, quando eu já estava aqui, o Jed começou a preparar novos materiais, um pouco diferentes, mas dentro dessa lógica de Estudos Dirigidos.

Mais jovem e com formação acadêmica mais recente do que a dos colegas, Airton percebeu que o modelo essencialmente tecnicista não era bem aceito pelos estudantes, porque era considerado lento, e teceu considerações acerca da personalidade de Tânia e do modo como reagia quando ele abordava a necessidade de atualização dos métodos para ensinar.

A Tânia, por outro lado, era muito fácil de trabalhar junto. Tudo o que nós combinávamos, ela fazia, ou encontrávamos para fazer. Além disso, ela era muito solidária. Mas ela tinha dificuldades de aderir a novas ideias, pois acreditava que o modelo que ela estava acostumada a adotar era muito bom e funcionava muito bem. Mas, por vezes, eu propunha algo e ela gostava, incorporava. Era dificil para mim, chegar até ela e dizer: "Olhe, o que você está fazendo está ficando velho". Eu a considerava uma ótima professora, percebia que os alunos a adoravam, mas em alguns momentos achava que ela poderia ir direto ao ponto, em um determinado conteúdo. Que, muitas vezes o uso de Estudos Dirigidos não se aplicava ou não era feito para aqueles alunos do Coltec, pois era muito lento. Alguns alunos reclamavam: "Ah, a gente fica só estudando sozinho". Afinal, estudar sozinho, deixar o aluno trabalhar, produzir, era a lógica dessa proposta. Mas a Tânia fazia um trabalho diferenciado, ela tinha o hábito de sistematizar os assuntos estudados, de ajudar os alunos e não deixá-los à própria sorte. Entretanto, era lento e exigia pouco dos estudantes.

Embora tenha sido crítico quanto aos métodos de ensinar aos quais Tânia conferiu um papel tão importante, foi clara a posição de Airton de respeito e admiração pelas carac- terísticas da professora. Ele acentuou a qualidade de seu trabalho no primeiro ano do Coltec: "acolhia muito bem os alunos, porque era muito mãezona", contribuindo para que os estudantes, nos anos seguintes, se mostrassem mais adaptados:

A Tânia fazia um trabalho bacana nesse sentido, ela fazia isso muito bem feito.

Airton chamou a atenção para a integração de Tânia a um grupo de colegas composto pelos professores Jed, Maria do Carmo, Tânia e Serjão..$^{18}$ Destacou a liderança de Maria do Carmo num núcleo que trabalhava com as mesmas ideias e materiais, mas comentou que todos participavam intensamente, inclusive Tânia, que, embora não tivesse "uma formação acadêmica avançada", estava sempre produzindo, estudando e pensando junto com os colegas. A referência de Airton à formação acadêmica de Tânia justifica-se pelo fato da professora, licenciada em Matemática pela Faculdade Newton Paiva, de Belo Horizonte, em 1977, ter posteriormente atingido como titulação máxima a especialização, realizada na universidade atualmente denominada Pontificia Universidade Católica de Minas Gerais, enquanto outros professores concluíram mestrado e doutorado em Educação ou Educação Matemática. Airton relacionou a formação de Tânia ao seu posicionamento no grupo, mas salientou que ele se alterou positivamente depois da aposentadoria dos colegas mais antigos:

Talvez, por não ter essa formação mais sólida em Educação Matemática, ela se posicionasse mais como colaboradora e não como sujeito. Inclusive, quando restou apenas ela desse grupo de professores, e ela ficou sozinha aqui comigo e o Chicão, ${ }^{19}$ ela passou a ter mais

18 Sérgio Veiga Dias, também chamado de Serjão, por ex -alunos e professores do Coltec, lecionou Matemática no colégio. Não foi possivel localizar esse professor para participação na pesquisa sobre as práticas de ensinar-aprender Matemática na escola.

19 Chicão era o apelido pelo qual era chamado Francisco de Assis Batista, professor de Matemática do Coltec 
poder, quis fazer mais. Sempre no espírito de mãezona, trazendo todos para trabalharem juntos. Isso era bom.-

Apesar da caracterização da professora Tânia como uma mãe acolhedora, afetuosa e agregadora, evidenciada em diversos depoimentos, uma sua ex-aluna, Poliana, entrevistada em 18/01/2016, apresentou uma visão distinta, tendo tecido comentários negativos sobre sua postura e metodologia de trabalho. Analisando-se como muito tímida e receosa de pedir ajuda, ela declarou ter sentido dificuldades de acompanhar os conteúdos de Matemática de forma autônoma, de acordo com a metodologia proposta pela docente.

[...] a metodologia da professora Tânia era assim: ela chegava, sentava lá na frente, entregava as apostilas aos estudantes e dizia que se o aluno tivesse dúvida, deveria ir até ela, pois ela não iria nas carteiras. $O$ atendimento era individual. Não havia correções no quadro. Como eu era muito tímida, não a procurava. [...] eu achava a professora Tânia muito fechada. Ela era muito bonita e os alunos eram fascinados por ela. Acredito que ela dava mais atenção a eles, pelo menos é a lembrança que tenho. Tânia entrava na sala e sentava-se assim, muito na dela. Eu, por outro lado, menina, adolescente, optava por ficar isolada.

Embora nos pareça relevante destacar esse ponto de vista de Poliana, que se contrapõe aos de alguns entrevistados, é preciso ressaltar o seu caráter de exceção, no que diz respeito à percepção da atuação de Tânia. Ele ilustra um aspecto primordial do uso da metodologia da História Oral - a possibilidade de um mesmo tema propiciar lembranças e interpretações divergentes, a serem consideradas pelo pesquisador.

de 1990 a 2010, que não foi entrevistado na pesquisa sobre a escola por não ter sido possivel localizá-lo. (MELILLO, 2018)

\section{Considerações sobre o percurso} (auto)biográfico da professora Tânia e a perspectiva de gênero

A narrativa de Tânia, aliada aos demais depoimentos colhidos na pesquisa de Melillo (2018), realça características socialmente consideradas femininas e/ou, em grande parte, próprias das mães, no relacionamento dessa docente com seus alunos e colegas ou em suas práticas de ensinar Matemática, a exemplo da escolha de dispor os estudantes em grupos, para discussões e atendimentos individualizados. Como comentamos antes, a palavra "mãezona" foi usada insistentemente para caracterizar a postura e as atitudes de Tânia. Tais aspectos chamaram nossa atenção e nos impulsionaram a nos debruçarmos sobre o perfil da professora.

A feminização do magistério é a expressão que se consagrou academicamente para significar o processo socio-político-cultural desencadeado pelo crescimento cada vez maior das mulheres na profissão docente nas sociedades ocidentais, a partir da segunda metade do século XIX. No Brasil, essa tendência se acentuou depois da República e o magistério, nos primeiros anos escolares, se tornou um espaço feminino e uma das poucas profissões socialmente aprovadas. Almeida (2008) pondera que o magistério se tornou a opção mais adequada às mulheres pela falta de acesso às demais profissões, "o que foi reforçado pelos atributos de missão e vocação, além da continuidade do trabalho do lar" (ALMEIDA, 2008, p. 141).

Louro (1997), ao discorrer sobre a participação feminina majoritária no magistério, enfatiza que eram considerados atributos naturais das mulheres a menor firmeza nas decisões, o excesso de sentimentos e a tolerância. Concomitantemente, eram caracterizadas como essencialmente femininas qualidades como abnegação, dedicação, altruísmo, paciência, afetividade, doação. 
Se assim se configurou a hegemonia da presença feminina no magistério primário, no ensino secundário brasileiro, a situação foi diferente. Até a década de 1930, não existiam cursos de formação específica para professores nesse nivel de ensino, de modo que os professores de Matemática foram, sobretudo, homens com formação militar ou engenheiros, sendo inexistente a participação feminina não somente nessa disciplina, mas em todas as disciplinas da escola secundária. Gradativamente, em todo o país, após o início do primeiro curso de licenciatura em Matemática, o da Universidade de São Paulo, em 1934, cresceu o número de cursos e também gradativamente foi ampliado o número de mulheres diplomadas em Matemática e habilitadas a lecionar no ensino secundário, de modo que a presença de professoras de Matemática se estabeleceu definitivamente nas décadas que se sucederam.

Na década de 1970, quando Tânia se graduou e se iniciou na profissão de docente de Matemática, havia crescido significativamente o número de mulheres lecionando a disciplina no ensino secundário. Entretanto, quando Tânia ingressou no Coltec, a menos de Maria do Carmo Vila, que passou a lecionar na escola no mesmo ano de 1979, a maior parte dos colegas docentes de Matemática era constituída por homens.

A força da caracterização usual das mulheres e, particularmente, das mulheres professoras, para as quais, ao longo do tempo, se enfatizaram alguns atributos "naturais" é enorme, tornando-a um elemento fundamental na construção histórica e social da feminilidade. Essa construção repercutiu e repercute ainda hoje nos modos de ser e estar no mundo das mulheres. Acreditamos, assim, que a associação das atitudes de Tânia a comportamentos femininos e, sobretudo, maternais, tanto por ela como por outros sujeitos, resulta de processos históricos muito anteriores ao tempo em que exerceu a profissão de professora de Matemática no Coltec.

Levando em conta essas considerações, torna-se pertinente estudar o perfil (auto)biográfico de Tânia à luz do conceito de gênero, que, de acordo com Louro (1995), coloca um contraponto às interpretações biologistas, que viam ou ainda veem nas diferenças sexuais explicações para as habilidades e as posições sociais hierarquicamente distintas de homens e mulheres, já que se destaca sua natureza socialmente construída. O conceito de gênero se opõe, assim, ao determinismo biológico baseado nas diferenças de sexo, que justifica a caracterização de homens e mulheres como seres qualitativamente distintos.

Conforme Vianna (2001/02), existem decorrências quando se abraça essa perspectiva. Uma delas, a nosso ver adequada ao estudo do percurso (auto)biográfico de Tânia, relacionase aos "significados masculinos e femininos que permeiam a história de professores e professoras e suas práticas escolares" (2001/02, p. 92). Esses significados, que se baseiam também nas diferenças entre os sexos, carregam de modo inegável e extremamente significativo a presença de uma construção social e cultural fundamentada nessas diferenças. Contribuem para a compreensão da inserção das mulheres na profissão docente, ligada a papéis femininos frequentemente menos valorizados na sociedade. "O cuidado, por exemplo, é visto como uma característica essencialmente feminina - para alguns uma responsabilidade natural, para outros, fruto da socialização das mulheres" (VIANNA, 2001/02, p. 93). A criação socio-histórica de um estereótipo feminino composto por qualidades como a docilidade, a afetividade, a sensibilidade e a preocupação de cuidar, contraposta a um estereótipo masculino que ressalta, por exemplo, a racionalidade e a agressividade, é imprescindivel para a análise do perfil de Tânia, construído primor- 
dialmente a partir do uso da metodologia da História Oral.

Cabe, porém, neste e em outros estudos, levar em consideração o gênero como uma categoria dinâmica, em construção e passível de transformação, e considerar que ele tem história, isto é, que o feminino e o masculino se transformam histórica e socialmente. Importa, ainda, a consciência de que, se o gênero é uma construção social, a sociedade não é capaz de impor unilateralmente atitudes e valores considerados adequados a meninos e meninas de modo que eles e elas os internalizem passivamente. Essa imposição não se faz sobre as pessoas "sem que estes mesmos sujeitos aceitem, rejeitem, contestem, adaptem, enfim, sem que, de múltiplas formas, eles participem desse processo" (LOURO, 1994, p. 42). Ao estudarmos o percurso (auto)biográfico de Tânia, reconhecemos, como recomenda essa autora, que "os sujeitos são ativos e ao mesmo tempo determinados, recebendo e respondendo às determinações e contradições sociais" (1994, p. 36).

Ao concluir este texto, enfatizamos reconhecer a:

[...] inexistência de uma verdade sólida, inquebrantável, intransponivel, definida e definitiva; o choque entre a pluralidade de pontos de vista distintos que essas fontes trazem à tona; a responsabilidade ao costurar, para sua pesquisa, essas fontes que the dão uma percepção parcial, mas nem por isso pouco nítida, da realidade em que está mergulhado. (GARNICA, 2007, p. 15)

Por isso, salientamos nossa convicção de que o percurso (auto)biográfico da professora Tânia, singularizado entre os docentes de Matemática do Coltec pela postura afetuosa e cuidadosa aqui ressaltada, não é o único que poderia ser construído. 0 que elaboramos foi, portanto, uma entre muitas possibilidades, tendo em vista as escolhas das vozes e das falas dos entrevistados na pesquisa realizada. Consideramos, porém, que este estudo, alicerçado na perspectiva autobiográfica, pode representar uma contribuição para o conhecimento da participação feminina na História da Educação Matemática.

\section{Referências}

ALBERTI, Verena. Manual de história oral. Rio de Janeiro: Editora Fundação Getulio Vargas, 2013.

ALMEIDA, Jane Soares de. A destinação das mulheres para educar meninos e meninas: como são construídos os paradoxos históricos. Educação e Linguagem, n. 18, p. 136-148, 2008.

CATANI, Denice Barbara; BUENO, Belmira Oliveira; SOUSA, Cynthia Pereira de; SOUZA, Maria Cecília Cortez Christiano de. História, memória e autobiografia na pesquisa educacional e na formação. In: CATANI, Denice Barbara; BUENO, Belmira Oliveira; SOUSA, Cynthia Pereira de.; SOUZA, Maria Cecília Cortez Christiano de. Docência, memória e gênero: estudos sobre formação. São Paulo: Escrituras, 2000. p. 15-47.

FARIA FILHO, Luciano Mendes de. 0 espaço escolar como objeto da história da educação: algumas reflexões. Revista da Faculdade de Educação [on-line], v. 24, n. 1, p. 141-159, 1998.

GARNICA, Antonio Vicente Marafioti. Manual de História Oral em Educação Matemática: outros usos outros abusos. Guarapuava: SBHMat, 2007.

GARNICA, Antonio Vicente Marafioti. História oral em educação matemática: um panorama sobre pressupostos e exercícios de pesquisa. História Oral, v. 18, n. 2, p. 35-53, jul./dez. 2015.

LOURO, Guacira Lopes. Gênero, história e educação: construção e desconstrução. Educação e Realidade, v. 20, n. 2, p. 101-120, 1995.

LOURO, Guacira Lopes. Mulheres na sala de aula. In: DEL PRIORE, M. (Org.). História das Mulheres no Brasil. São Paulo: Contexto/Ed. UNESP, 1997. p. 443-481. LOURO, Guacira Lopes. Uma leitura da história da 
educação sob a perspectiva do gênero. Projeto História, n. 11, p. 31-46, 1994.

MEIHY, José Carlos Sebe Bom; RIBEIRO, Suzana. Guia prático de história oral: para empresas, universidades, comunidades, famílias. São Paulo: Contexto, 2011.

MELILLO, Kelly Maria de Campos Fornero Abreu de Lima. História de práticas de ensinar-aprender Matemática no Colégio Técnico da UFMG-Coltec (19691997). 2018. 706 f. Tese (Doutorado em Educação) - Faculdade de Educação, Universidade Federal de Minas Gerais, Belo Horizonte, 2018.

MUNIZ, Nancy Campos. Relatos de memórias: a trajetória histórica de 25 anos da Sociedade Brasileira de Educação Matemática (1988-2003). São Paulo: Livraria da Física, 2013.

PASSARINHO no Colégio Técnico, entusiasmado. Diário da Tarde, 03 dez. 1970, p. 8.

SAVIANI, Demerval. História das ideias pedagógicas no Brasil. Campinas, SP: Autores Associados, 2007.
SOUZA, Maria Cecília Cortez Christiano de. A escola e a memória. Bragança Paulista, SP: IFAN-CDAPH; Editora da Universidade São Francisco - EDUSF, 2000.

TROTTA, Fernando; IMENES, Luiz Márcio Pereira; JAKUBOVIC, José. Matemática aplicada. São Paulo: Moderna, 1980.

UFMG formará técnicos de laboratórios médicos. Jornal do Brasil, Rio de Janeiro, 10 nov. 1969. 10 Caderno: Mercado de Trabalho, p. 47.

VIANNA, Cláudia Pereira. O sexo e o gênero da docência. Cadernos Pagu, v. 17/18, p. 81-103, 2001/02.

VILLAS, Sara. Formas de sociabilidade entre alunos de uma escola de ensino médio/técnico. 2009. 228 f. Dissertação (Mestrado em Educação) - Faculdade de Educação, Universidade Federal de Minas Gerais, 2009.

Recebido em: 28/01/2019

Aprovado em: 30/04/2019

Kelly Maria de Campos Fornero Abreu de Lima Melillo é Doutora em Educação pela Universidade Federal de Minas Gerais. Professora do Setor de Matemática do Colégio Técnico da Universidade Federal de Minas Gerais, Brasil. Grupo de Pesquisa: História Oral e Educação Matemática (GHOEM).e-mail: kellyfornero@yahoo.com.br

Rua Elson Nunes de Souza, 444, apto. 202. Castelo. Belo Horizonte, MG. CEP 30840-530. Telefone: (31) 987865905.

Maria Laura Magalhães Gomes é Doutora em Educação pela Universidade Estadual de Campinas. Bolsista de Produtividade do CNPq. Professora Titular do Departamento de Matemática. Docente do Programa de Pós-Graduação em Educação da Universidade Federal de Minas Gerais, Brasil. Grupo de Pesquisa: História Oral e Educação Matemática (GHOEM). e-mail: mlauramgomes@gmail.com

Rua Coletor Celso Werneck, 174 apto. 501. Santo Antônio. Belo Horizonte, MG. CEP 30350-010. Telefones: (31) 3296-58-84 e (31) 99949-81-16. 